\title{
Diálogos de gênero na educação: considerações sobre o projeto Lei Maria da Penha vai às escolas
}

\author{
Kristine Kelly de Albuquerque ${ }^{1}$ (iD 0000-0003-4363-4364 \\ 'Centro Universitário do Vale do Ipojuca WYDEN, Caruaru, PE, Brasil. 5 \\ 5028-120-admissoes@unifavip.edu.br
}

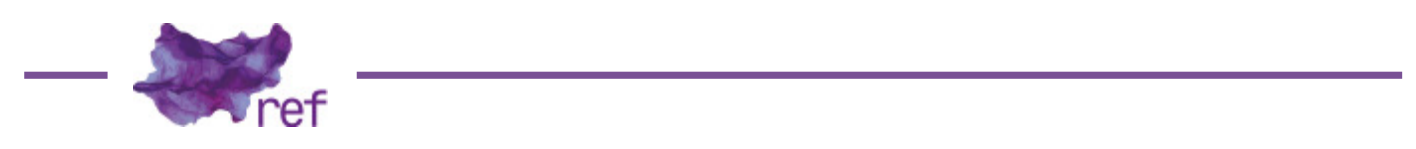

Resumo: A violência doméstica e familiar contra a mulher se configura como um fenômeno social complexo e multifatorial. Suas formas de expressão e (in)visibilidades são marcadas por uma cultura patriarcal que traveste as desigualdades de gênero como inerentes ao desenvolvimento histórico da humanidade. A erradicação desta forma de violação dos Direitos Humanos perpassa pela necessidade da prevenção de suas diversas faces. Neste artigo busca-se apresentar o projeto Lei Maria da Penha vai às escolas e discutir sobre os seus efeitos ao enfrentamento destas violências. Levar tal tema ao âmbito escolar justifica-se por este ser um dos espaços primários de socialização, responsável por uma formação crítica e cidadã. Conclui-se que as oficinas têm sido espaço fértil de diálogo e construção de novas formas de se pensar as relações de gênero, contribuindo para uma sociedade mais equânime. Palavras-chave: gênero; educação; Lei Maria da Penha; violência contra a mulher; direitos humanos.

Gender Dialogues in Education: Considerations about The Project Law Maria Da Penha Goes to Schools

Abstract: Domestic and family violence against women is configured as a complex and multi factorial social phenomenon. Their forms of expression and (in)visibilities are marked by a patriarchal culture that crosses as gender inequalities as inherent in the historical development of humanity. The eradication of this form of violation of Human Rights permeats to the need to prevent its various faces. The present study aims to present the "Law Maria da Penha Goes to Schools" Project an discuss its effects in dealing with these violations. Take this issue to the school environment is justified because it is one of the main socialization, responsible for training and critical citizen. It is concluded that the workshops have been fertile space for dialogue and construction of new ways of thinking about gender relations, contributing to a more equitable society.

Keywords: Gender; Education; Law Maria da Penha; Violence against women; Human rights.

\section{Introdução}

Neste artigo tem-se por objetivo expor as experiências e resultados decorrentes dos estudos teóricos e empíricos vivenciados por meio do programa de extensão universitária "Acolhimento e Acompanhamento Psicossocial às Mulheres Vítimas de Violência Sexista, aos Autores de Violência e à Comunidade", vinculado ao Laboratório de Prática Psicológica e Organizações Sociais LAPOS, no DeVry/UNIFAVIP. Utiliza-se como referência para fundamentar estas discussões a visão teórico-metodológica feminista, buscando analisar e refletir sobre questões cotidianas a partir do gênero como categoria de análise sociocultural, bem como da psicologia social enquanto adoção de uma postura crítica frente às instituições, organizações e práticas da sociedade atual.

Desta forma, as intervenções realizadas a partir deste Projeto se constituem como ferramentas que pretendem fomentar a desfamiliarização e consequente desnaturalização de práticas produtoras e reprodutoras de desigualdades de gênero na sociedade. O tema se mostra de grande relevância, considerando que o patriarcado e seus efeitos permanecem justificando 
crenças sociais que são disseminadas na formação de cidadãos e cidadãs, propagando diversas formas de desigualdades e discriminações, dentre elas a prática da violência contra a mulher nos âmbitos doméstico e familiar.

Segundo o Plano Estadual para Prevenir, Punir e Erradicar a Violência Contra as Mulheres do Governo do Estado de Pernambuco (GOVERNO DO ESTADO DE PERNAMBUCO, 2008), transformar este cenário construído em bases patriarcais implica, além da punição, trabalhar com a prevenção de maneira sistemática, atuando nesse processo histórico para a construção de novos valores. Ainda segundo o referido Plano Estadual (GOVERNO DO ESTADO DE PERNAMBUCO, 2008), a escola se torna o espaço fundamental para discutir questões sobre gênero, raça e etnia, posto que daí serão formadas as futuras gerações que sucederão as atuais, para que assim possam ter a compreensão sobre as relações humanas na vida em sociedade.

Assim, a partir deste estudo e das discussões propostas aqui, pretende-se colocar em pauta como o diálogo sobre gênero, articulado ao ambiente escolar, pode contribuir para a prevenção e o enfrentamento da violência contra a mulher. Para um maior entendimento e contextualização desta análise, será imprescindível apresentar as articulações acerca das concepções de gênero, violência de gênero e violência contra a mulher com a afirmação-violação dos Direitos Humanos e a importância da educação nesse cenário.

\section{Gênero: desdobramentos, deslocamentos e reconhecimentos}

O debate sobre gênero como categoria histórica e cultural começou dentro do movimento feminista, "na tentativa de compreender as desigualdades entre homens e mulheres" (Lady ALBERNAZ; Márcia LONGHI, 2009, p. 80). O feminismo, enquanto movimento que propõe a igualdade de direitos para homens e mulheres, buscava não apenas descrever como aconteciam tais desigualdades, mas desvelar as configurações históricas que as geravam.

É nesse ponto que os estudos sobre cultura são fundamentais [...]. Por meio da comparação das diferentes sociedades é possível afirmar que o comportamento humano é decorrente da cultura, do arranjo de valores que o guiam, e não por intermédio de uma determinação biológica. Sendo assim, a explicação das diferenças entre homens e mulheres também decorre da cultura. A biologia, portanto, não determina os comportamentos humanos, o que os homens e as mulheres fazem decorre principalmente da leitura cultural sobre seus corpos. Se estas leituras são uma criação humana, então nós podemos fazer novas escolhas e alterar o que é tido como imutável no comportamento humano (ALBERNAZ; LONGHI, 2009, p. 82).

É desse modo que a categoria gênero foi cunhada dentro do movimento feminista, com a finalidade de "compreender como a relação entre natureza e cultura opera como justificativa das desigualdades entre homens e mulheres" (ALBERNAZ; LONGHI, 2009, p. 82). Assim, buscava-se entender as conexões entre natureza e cultura como produtoras de modos de ser do humano. Não se trata de anular as diferenças biológicas, mas de compreender o gênero como uma classificação cultural proveniente da vida em sociedade e que regula as relações sociais.

Desse modo, é possível perceber que o conceito de gênero como uma "construção social do masculino e do feminino" (Heleieth SAFFIOTI, 2004, p. 45) é um ponto de partida que permite interrogações inéditas aos modos de ser do humano, abrindo novos horizontes de investigação e compreensão quanto aos lugares sociais e culturais assumidos por homens e mulheres.

Colocar o debate sobre gênero no campo das relações sociais permite ainda ampliar o olhar para o processo de construção destas representações do masculino e do feminino. É indispensável considerar os marcadores sociais que o cercam e o geram, como raça, etnia e classe, entre outros, pluralizando o próprio entendimento dessas relações entre os gêneros e suas intersecções. Ainda, essas representações existentes vão além de assumir papéis sociais femininos ou masculinos, uma vez que na dinâmica relacional o gênero passa a constituir a identidade dos sujeitos e, portanto, é mutável e múltipla. De tal modo, expande-se a noção de que existiriam papéis pré-determinados a serem representados por homens e mulheres, sendo então a vivência dos gêneros mais uma das faces constituintes da identidade humana (Guacira LOURO, 1997).

A partir dessas compreensões foi possível chegar à demarcação de violência de gênero, que deriva de uma forma de organização social que privilegia o masculino sobre o feminino, baseada na hierarquia estabelecida em uma cultura patriarcal (ALBERNAZ; LONGHI, 2009). Violência de gênero compreende diversos tipos de violências, e não apenas contra as mulheres. Aqui o foco será direcionado à forma da violência doméstica e familiar contra a mulher, pois este é o cerne da atuação do projeto de extensão universitária do LAPOS.

A violência contra a mulher é um fenômeno complexo, multidimensional e multifatorial que abrange múltiplas formas de expressão e (in)visibilidades. Por ser "justificado" implicitamente pelas percepções sociais de gênero em uma cultura patriarcal, já se encontra naturalizado na sociedade (Katherine BANDEIRA; Elba AMORIM, 2013; SAFFIOTI, 2004). Entretanto, a partir da compreensão de que tais determinações são construções sociais e históricas, é possível promover formas de reflexão e desnaturalização de tais crenças na coletividade, produzindo a condição 
de possibilidade de outras novas formas de ser homem e mulher e, assim, também produzir relações mais equânimes na sociedade.

O fenômeno da violência doméstica e familiar contra a mulher permaneceu durante décadas como pertencente unicamente ao âmbito privado, pois a família era concebida como uma unidade privilegiada e idealizada. Dessa forma, o Estado só poderia intervir em situações de violência no espaço público, ficando o lar sob a responsabilidade do chefe e provedor da família. Assim, a mulher que sofresse agressão dentro de sua própria casa não possuía nenhum respaldo na lei ou rede de apoio social, devendo permanecer subserviente ao esposo. Com a evolução do país nas ordenações jurídicas e as manifestações coletivas de grupos feministas, este fenômeno cada vez mais foi ganhando visibilidade (CONSELHO FEDERAL DE PSICOLOGIA, 2012).

Dentre os termos lógicos e legais que favoreceram a visibilidade da mulher na sociedade, têm-se: a Declaração Universal dos Direitos Humanos (ONU, 1948); a Constituição da República Federativa do Brasil (BRASIL, 1988); a Convenção sobre a Eliminação de Todas as Formas de Discriminação contra a Mulher, 1979 (BRASIL, 2002); a Convenção Interamericana para Prevenir, Punir e Erradicar a Violência Contra a Mulher (BRASIL, 1994); o Plano Nacional de Políticas para as Mulheres, 2005 (BRASIL, 2006b); a Lei no 11.340 (BRASIL, 2006a). Além dos citados, existem também outros aportes legais de igual importância para a compreensão global do tema, porém estes foram mencionados por serem os que se tornaram referência para a adoção de outros instrumentos (CONSELHO FEDERAL DE PSICOLOGIA, 2012).

Em se tratando da conceituação e punição da violência contra a mulher baseada no gênero, a mais conhecida e influente é a lei 11.340, promulgada em 07 de agosto de 2006, tornando-se popularmente conhecida como Lei Maria da Penha, crédito concedido pela história de luta de Maria da Penha Maia Fernandes contra seu marido e agressor. Essa vitória na legislação veio tipificar a violência doméstica e familiar contra a mulher, antes subestimada pelos juristas, e suas manifestações diversas, além de outras mudanças inovadoras, dentre elas a punição mais severa ao autor de violência (BRASIL, 2006a). Sua definição de violência contra a mulher compreende

qualquer ação ou omissão baseada no gênero que the cause morte, lesão, sofrimento físico, sexual ou psicológico e dano moral ou patrimonial, no âmbito da unidade doméstica [...], no âmbito da família [...], em qualquer relação íntima de afeto (BRASIL, 2006, p. 13).

Ainda, a lei define as formas de violência doméstica e familiar contra a mulher: física, psicológica, sexual, patrimonial e moral, além de prever medidas de punição e reeducação ao homem autor de violência e proteção e assistência à mulher em situação de violência (BRASIL, 2006). Importante destacar que esses atos de violência são pontuais, intercalados entre demonstrações de afeto, buscando, com isso, o controle psicológico e emocional da companheira, e são caracterizados por um ciclo de violência," "de acordo com o qual existe um padrão de funcionamento em um ciclo de três fases sucessivas: a primeira seria a fase da tensão, a segunda, da explosão, e a terceira e última, a fase da lua de mel" (CONSELHO FEDERAL DE PSICOLOGIA, 2012, p. 68).

A mulher que se encontra no interior desse ciclo demora a perceber tal situação, e geralmente ela não consegue sair desse padrão sem a ajuda de alguém. Por isso é essencial desmistificar certas frases que chegam a produzir sentidos como verdade absoluta, tais como "mulher gosta de apanhar" ou "ela mereceu". A compreensão da legitimidade destes discursos só é possível por meio da leitura crítica da arraigada cultura patriarcal na qual a sociedade está inserida, dando voz e vez a práticas machistas, sexistas e misóginas.

A afirmação dos Direitos Humanos das Mulheres nesse contexto justifica-se por ser esta violência também uma violação dos princípios de dignidade da vida humana, afetando o seu direito à vida, à saúde, dentre outros. Sabendo que a ocorrência desta violência afeta não só uma, mas várias dimensões da vida das mulheres, atuar na direção de garantia desses direitos significa criar a condição necessária para a sua efetivação. O Plano Nacional de Educação em Direitos Humanos (BRASIL, 2007) se constituiu na direção de atuar como

uma proposta de um projeto de sociedade baseada nos princípios da democracia, cidadania e justiça social, [...] reforçando um instrumento de construção de uma cultura de direitos humanos, entendida como um processo a ser apreendido e vivenciado na perspectiva da cidadania ativa (BRASIL, 2007, p. 13).

\footnotetext{
O ciclo da violência doméstica se caracteriza por um padrão de comportamento abusivo que pode ser identificado nas relações afetivas. O termo foi cunhado pela psicóloga norte-americana Lenore Walker em 1979. As fases desse ciclo são marcadas por momentos de agressividade por parte do autor da agressão, como ofensas verbais e controle de atividades cotidianas, seguido pelas agressões físicas, como tapas, socos e empurrões, e uma fase de calmaria, ou lua de mel, na qual há um pretenso arrependimento, pedidos de perdão e promessas de que aquilo não irá acontecer novamente. Mais informações podem ser encontradas no site do Instituto Maria da Penha: http:// www.institutomariadapenha.org.br/violencia-domestica/ciclo-da-violencia.html.
} 
Assim, a compreensão de que a garantia dos direitos deve se dar a partir do diálogo no espaço escolar, seja este básico ou superior, se torna uma condição de possibilidade para a promoção da democracia, pois é por meio da educação que se inicia o desenvolvimento de uma consciência crítica e reflexiva sobre as relações da vida humana e os problemas da sociedade.

É imprescindível que a escola, sendo espaço democrático de educação, possa refletir coletivamente acerca dos valores que serão norteadores da elaboração dos seus planos político-pedagógicos, contemplando a inclusão de temas relevantes para os seus educandos, a fim de que tenhamos êxito na formação de crianças, adolescentes e adultos comprometidos com a busca por uma sociedade mais justa e igualitária (Raqueline BARRETO; Josué SILVA, 2015, p. 07).

O Estado brasileiro, que tem por princípio a afirmação dos Direitos Humanos, busca efetivar a garantia de direitos por meio de políticas públicas que assumem os problemas emergentes da sociedade e fomentam discussões e práticas que levem à solução destes. Por meio da educação, então, é possível ampliar a consciência cidadã sobre estas questões, e o enfoque da educação em direitos humanos se baseia nessas diretrizes, almejando a "construção de uma sociedade baseada na promoção da igualdade de oportunidades e da equidade, no respeito à diversidade e na consolidação de uma cultura democrática e cidadã" (BRASIL, 2007, p. 11).

Assim sendo, diante da realidade em que se vive atualmente, marcada por opressões e exclusões diversas, a educação se torna o espaço primário de construção de vias de aprendizagem que enfrentem tais discursos opressores e segregacionistas, possibilitando assim a transformação destes, uma vez que é no espaço escolar que se aprende a viver em sociedade. Portanto, ao se privilegiar uma educação interdisciplinar em Direitos Humanos, sob o prisma de gênero, será dada a condição de possibilidade de formação de uma geração que buscará viver de forma mais justa e igualitária, em uma cultura de paz e respeito (BARRETO; SILVA, 2015).

Nessa direção, este projeto de extensão atua como uma mola propulsora de desmistificação e desnaturalização dos padrões de gêneros, de masculinidades e feminilidades, permitindo novos olhares e novas percepções aos modos de ser de homens e mulheres. Ainda, de forma indissociável, trabalha para prevenir e erradicar a violência contra a mulher. Por meio das oficinas nas escolas pode-se estabelecer uma via de informação aos estudantes e, consequentemente, aos seus familiares e comunidade, contribuindo para a disseminação da luta contra a violência e a formação de uma cidadania responsável. Além disso, tal forma de atuação corrobora os princípios da extensão universitária, que articula teoria e prática na interação universidade e sociedade, democratizando o saber (FORPROEX, 2012).

\section{Metodologia}

A abordagem qualitativa de pesquisa norteia o presente estudo. Inicialmente foi utilizado o método bibliográfico-exploratório (Antônio GIL, 1999), a fim de verificar o curso atual das pesquisas articulando gênero, educação e violência contra a mulher, momento em que puderam ser percebidos alguns relatórios e orientações produzidos sobre o projeto Lei Maria da Penha vai às escolas em outros estados brasileiros, porém praticamente inexistem relatórios e pesquisas sobre os resultados do projeto no estado de Pernambuco.

A metodologia utilizada na elaboração e execução do Projeto foi a de pesquisa-ação, uma vez que se trata de uma pesquisa social com base empírica, objetivando uma atuação participante sobre determinada questão (GIL, 1999). Com o objetivo de fomentar a discussão sobre o tema, as oficinas foram planejadas de modo a dar voz aos estudantes, rompendo com a visão de verdade unilateral e verticalizada de um suposto saber. Assim, intercalaram-se as experiências dos estudantes com os conceitos embasados na teoria, visando à congruência com os princípios da extensão universitária, que propõe a interação dialógica entre sociedade e academia, objetivando assim a transformação social (FORPROEX, 2012).

As oficinas se constituem como uma ferramenta de intervenção psicossocial, que têm como propósito intervir em um grupo específico sobre um determinado tema, que deve ser relevante para o grupo em questão. É necessário realizar o levantamento da demanda do grupo, o que foi realizado a partir da mediação de uma profissional da Secretaria da Mulher junto à Secretaria de Educação do município. O planejamento, realização e avaliação da intervenção psicossocial incluem: um caráter científico; preocupação em gerar mudança e desenvolvimento; foco em grupos, instituições e/ou comunidades; ação sobre os problemas atuais da sociedade; intervenção focada; caráter predominantemente preventivo; leva em conta o contexto social e cultural; inclui a diversidade do grupo, instituição e/ou comunidade (Kathia NEIVA, 2010).

A partir da análise de conteúdo (Laurence BARDIN, 2007) será realizada a análise e interpretação de fragmentos selecionados da narrativa dos estudantes, a fim de compreender as crenças e percepções destes sobre os padrões de gênero e sua relação com o fenômeno da violência contra a mulher. 
A seguir serão discutidos os resultados percebidos com base nas atividades realizadas pelos estudantes extensionistas. Mas antes importa delinear o Projeto e seus objetivos.

\section{Contextualizando o projeto Lei Maria da Penha vai às escolas}

O projeto Lei Maria da Penha vai às escolas surgiu em 2012, no âmbito da Secretaria Especial da Mulher e Direitos Humanos do município de Caruaru-PE, com o objetivo de difundir conhecimentos e desenvolver uma consciência crítica acerca da violência contra a mulher no âmbito doméstico e familiar aos estudantes da rede privada, municipal e estadual de ensino, colaborando assim para a prevenção e erradicação deste problema.

Inicialmente o Projeto era desenvolvido pelos profissionais da Secretaria por meio de palestras, que aconteciam de forma pontual. Contudo, foi percebido que, durante as palestras, surgia uma mobilização crescente e questionamentos diversos por parte dos estudantes, não havendo um espaço posterior para dialogar com eles sobre essas ideias que emergiam. Assim, houve um redimensionamento do programa, que passou a operar no formato de oficinas e de forma sistemática, podendo então abrir espaços para uma maior interação e uma construção coletiva sobre o tema.

Três anos após, entre o fim de 2015 e o início de 2016, o programa transformou-se em projeto, sendo respaldado por um decreto municipal pelo então prefeito José Queiroz de Lima (DIÁRIO OFICIAL DO MUNICÍPIO DE CARUARU, 2016). Em parceria com um centro universitário, por meio da extensão universitária, graduandos do curso de Psicologia, sob a supervisão das orientadoras do Projeto e de professoras do curso, realizam as oficinas em escolas do município e/ ou do estado, construindo ferramentas para que estes sujeitos, futuros cidadãos, possam viver uma vida com menos violência e mais igualdade.

A ideia é pioneira em Pernambuco, sendo referência para outras cidades do estado. Também já se encontram projetos com formatação similar em outros estados do país, a exemplo do Pará, Brasília e Mato Grosso do Sul. Todavia, o diferencial do projeto realizado em Caruaru-PE caracterizase nas oficinas de caráter psicopedagógico e na sistematicidade.

A Secretaria Especial da Mulher e Direitos Humanos do município de Caruaru-PE idealizou tal ideia como uma maneira de repensar as formas de enfrentamento à violência contra a mulher. Isso porque a escola se constitui como um dos pilares mais importantes de formação do indivíduo, e é neste espaço que os sujeitos são injetados pela cultura patriarcal predominante em nossa sociedade: aprendem os modos de ser de meninos e meninas, e a se comportarem como tal, seguindo os padrões de masculinidades e feminilidades, que são interiorizados e naturalizados. Quando há o desvio destes comportamentos tidos como padrão, surgem as discriminações e práticas de exclusão, que retroalimentam as desigualdades baseadas no gênero (BANDEIRA; AMORIM, 2013).

Com isso, acreditando que a equidade de gênero precisa começar pela desnaturalização de tais estereótipos, pela percepção de que eles são socialmente construídos, a proposta das oficinas como ferramenta de intervenção visa apresentar estas formatações culturais aos estudantes e como elas passam a servir de justificativas para a violência contra a mulher, perpetuando socialmente essas crenças como se fossem naturais e imutáveis. Ainda, essa atuação vem a concretizar as diretrizes do Plano Nacional de Políticas para as Mulheres (BRASIL, 2013) e o Plano Estadual para Prevenir, Punir e Erradicar a Violência Contra as Mulheres do Governo do Estado de Pernambuco (GOVERNO DO ESTADO DE PERNAMBUCO, 2008).

Falar em promoção de equidade nas relações de gênero implica a (re)afirmação dos Direitos Humanos e da Democracia. Considerando que a Constituição da República Federativa do Brasil, promulgada em 1988, declara que todo ser humano é igual no atributo de direitos e deveres, sem distinção de gênero, e tendo em vista que a Declaração Universal dos Direitos Humanos de 1948 configura-se como um coletivo de direitos e garantias inerentes ao ser humano enquanto condição para uma vida digna, igualmente sem distinção de gênero, promover esses espaços de reflexão crítica sobre as relações de gênero se constitui em um modo de combate às desigualdades, opressões e exclusões e o comprometimento com a busca por uma sociedade mais justa e igualitária (BARRETO; SILVA, 2015).

\section{Resultados e discussão}

As oficinas que fundamentaram a análise do presente estudo foram realizadas entre outubro e novembro de 2016 em uma escola da rede municipal de ensino em Caruaru-PE. É importante ressaltar que estas oficinas foram adotadas aqui como um recorte do Projeto para a presente análise, e que o Projeto continua em vigor atualmente, apenas tendo alterado o corpo de discentes que o realizam. Ainda, tal modificação do corpo de discentes se faz necessária pelo caráter da extensão universitária na referida instituição de ensino, mas o período mínimo de permanência estabelecido é de um ano, podendo ser prorrogado.

O grupo de extensionistas atua em grupos subdivididos com o objetivo de obter maior abrangência de estudantes participantes das oficinas. No período referido ocorreram quatro 
oficinas, com média de 20 estudantes em cada uma delas, e a faixa etária abrangeu de 09 a 14 anos. Participaram as turmas do $6^{\circ}$ e $7^{\circ}$ anos do ensino fundamental. $O$ planejamento e a elaboração das oficinas se deram nos encontros com as supervisoras do projeto, momento em que também houve a dramatização destas com o objetivo de facilitar o desempenho posterior.

Por haver mais de um grupo realizando as oficinas, cada um planejou um roteiro singular sobre como desenvolvê-las. No entanto, considerava-se a importância da ludicidade para facilitar o envolvimento dos estudantes e o momento posterior de reflexão sobre a oficina, articulando as dinâmicas vivenciadas com a teoria apresentada e com as narrativas dos estudantes. As oficinas tinham duração média de duas horas. Os temas levantados a partir das vivências estimulavam a discussão sobre a temática, promovendo a construção coletiva do saber.

O primeiro passo após a apresentação dos estudantes e do objetivo da oficina foi propor uma dramatização de algumas cenas previamente escolhidas pelos organizadores. Com isso, o intuito era de apreender quais as percepções que eles tinham sobre tais situações e, a partir disso, construir o diálogo sobre os conceitos ligados a essas percepções. Por serem situações que já acontecem na cultura em questão em decorrência de sua construção historicamente patriarcal, os comportamentos representados pelos alunos indicariam como eles veriam tais situações e quais seriam suas possíveis consequências. Ao lhes serem apresentados os pensamentos que estariam por trás destes comportamentos, estar-se-ia convidando-os para uma nova forma de olhar o mundo e para uma mudança nas suas interações sociais.

Para esse momento, a sala foi dividida em quatro grupos. Os temas sugeridos para a dramatização foram os seguintes:

A) Diego e Daniela vão sair para jantar para comemorar seis meses de namoro. Diego vai encontrar Daniela em sua casa para saírem juntos, mas, ao vê-la, pede para ela voltar e se trocar, pois sua roupa está muito curta e provocante. O que acontece a seguir?

B) Marcos chega em casa tarde e está estressado com o seu chefe. Sua esposa, Marília, sugere que eles saiam para jantar. Ele não quer, mas ela tenta convencê-lo. Marcos se irrita e grita com a esposa, xingando-a. O que acontece a seguir?

C) Otávio e Olívia namoram há quatro anos. Certo dia, Otávio faz uma surpresa e pede Olívia em casamento. Olívia pensa um pouco, e diz que não tem certeza se é isso o que ela quer para a sua vida. Otávio se irrita e pega forte em seu braço, dizendo que se ela não for dele, não será de mais ninguém. O que acontece a seguir?

D) Uma mulher está voltando do trabalho e passa por uma rua pouco movimentada. Um homem passa por ela, assovia e diz que ela é linda. Ela não responde e segue o seu caminho. Ele para de andar e a insulta, chamando-a de metida e vadia. O que acontece a seguir?

O grupo que ficou com a primeira cena a representou da seguinte forma: o homem chamavaa de "piriguete" e pedia para ela trocar de roupa, caso contrário não iriam mais sair, ao que a mulher respondeu que a roupa que ela usava não dizia nada sobre o seu caráter, e ela iria usar o que ela quisesse.

Situando essa experiência em uma cultura marcada pelo patriarcado, que pode ser concebido como um esquema de dominação e exploração das mulheres (SAFFIOTI, 2004; Cecília SANTOS; Wânia IZUMINO, 2005), abrangendo uma dimensão simbólica e inconsciente de representações sociais da dominação masculina (Pierre BORDIEU, 2010), pode-se perceber a naturalização do comportamento abusivo do namorado para com a namorada. Naturalização essa que alimenta uma cultura do estupro, na qual a mulher é objetificada sexualmente e tem seu discurso deslegitimado socialmente.

Ao olharmos para o conceito de dominação patriarcal enquanto controle social dos homens para com as mulheres, tendo essa relação de poder sendo perpetuada pela socialização desde a infância, podemos entender que essas concepções são vistas como naturais porque assim é ensinado. Confrontar esse lugar de subordinação do feminino, questionando-o e deslocando-o em direção a relações de igualdade, é o primeiro passo para promover a ruptura dessa visão de controle e poder.

Ao perceber que muitos estudantes concordavam com essa visão, posto que era o que predominantemente conheciam, a discussão levantada pela equipe responsável pelas oficinas buscou apresentar os motivos dessa naturalização e, assim, promover reflexões que quebrassem esse paradigma. Foram trazidas à tona as definições de machismo, sexismo e misoginia, e como estas visões de mundo atuam na redução e na rigidez de modos de ser masculinos e femininos, conectando esse diálogo às definições de gênero e como isso influencia nas diversas formas de violência contra a mulher. Algumas meninas da turma já traziam um pouco desse entendimento e gostaram de poder reafirmar suas convicções quanto a isso, colocando que "ninguém deveria poder julgar uma mulher pelas roupas que ela usa ou pelas coisas que ela faz, cada um é livre para ser o que quiser".

A segunda cena foi representada por dois meninos, pois as meninas do grupo sentiram-se tímidas no momento. Eles achavam que era obrigação da mulher estar com a janta pronta quando o marido chegasse do trabalho, e quando isso não acontecia o marido poderia responder com 
violência. Outro grupo se manifestou quanto a isso, colocando que as mulheres não possuíam obrigação nenhuma com seus maridos e que nenhum motivo justificaria o comportamento violento.

Percebe-se que o sistema sociopolítico dominante, atrelado ao desenvolvimento histórico de uma sociedade patriarcal, se alinha às significações simbólicas e empíricas de um patriarca, isto é, uma autoridade paterna e um chefe de família. Ao ser incorporado aos estudos feministas, introduzindo a relação de poder marcada pela dominação masculina e opressão feminina, o termo patriarcado pretende ampliar a descrição deste de atitudes individuais para um sistema e conjunto de ações que "impregna e comanda o conjunto das atividades humanas, coletivas e individuais" (Christine DELPHY, 2009, p. 178). Assim, essas relações de poder ultrapassam a esfera privada e se mesclam às questões públicas.

Essa dinâmica de poder e violência, ainda que não seja estática, é predominantemente um fator de vulnerabilidade para as mulheres (SANTOS; IZUMINO, 2005). Ao se perceber em uma relação abusiva, a mulher tem sua autonomia muitas vezes limitada pela subjetividade marcada pelos elementos de sua socialização. Disso pode decorrer, entre outros pensamentos, que seja sua própria culpa tal comportamento do companheiro e que sua agressão não foi intencional.

A escola, sendo uma das instituições primárias de socialização de novas gerações, muitas vezes corrobora a reprodução de comportamentos que se adéquem às categorias de gênero, eliminando deste o caráter cultural e afirmando unicamente suas diferenças biológicas, que atuam como diferenças hierárquicas. Nesse sentido, a escola está moldando identidades binárias, rígidas e desiguais, que propagam esses binarismos e essas desigualdades na sociedade. Paralelamente, acredita-se que é na escola que se encontra o papel político e cidadão transformador de realidades injustas, que produzem sofrimentos e vulnerabilidades (LOURO, 1997; Miguel MAHFOUD, 1999).

Ao sair do lugar de observador, no papel de extensionista, e tentar interferir na continuidade desse padrão de desigualdades, bem como estimular tais reflexões nos estudantes, acredita-se na potencialidade do espaço escolar enquanto comunidade. Corroborando Louro (1997), desestabilizar essas visões e problematizar o que é tido como natural implica a disposição para intervir nestes jogos de poder e, com isso, possibilitar outros caminhos de ser e estar no mundo.

Na terceira cena, o grupo opinou que a mulher deveria dizer que não queria se casar e ir embora, e que o homem iria aceitar essa decisão e não faria nada com ela. Outro grupo questionou esse desfecho, comentando que na realidade não era tão fácil assim, pois a mulher poderia sofrer alguma reação violenta do namorado, que poderia até mesmo matá-la.

Retomando o contexto de análise a partir das relações de poder, a objetificação da mulher em um relacionamento afetivo leva à noção de que ela seria uma posse e de que o companheiro teria direito sobre ela. Tal entendimento molda um relacionamento não saudável, abusivo e propenso à ocorrência de violência, posto que é nocivo e privilegia a posse sobre o afeto.

Segundo os dados do Mapa da Violência 2015 (ONU MULHERES, 2015), o Brasil atingiu o $5^{\circ}$ lugar no ranking de homicídios de mulheres, sendo que o número de assassinatos é de 4,8 a cada 100 mil mulheres. Tanto a mulher na situação de vítima, quanto a população em geral, reconhece o risco à vida das mulheres em situação de violência doméstica e familiar. Esse consenso reforça a necessidade de que o Estado e a sociedade ofereçam o apoio necessário para a ruptura do ciclo de violência, bem como criem ferramentas para a prevenção desta.

Os índices de feminicídio² no Brasil, bem como o aumento de denúncias de casos de violência doméstica, alertam para a necessidade de reeducar a sociedade e promover 0 entendimento sobre esses padrões nocivos e suas consequências. O enfrentamento da violência contra a mulher também deve partir de sua prevenção, e o espaço escolar se constitui como lugar privilegiado de promoção de diálogo e informação. Muitos estudantes afirmaram ter sido esse o seu primeiro contato com essa discussão de gênero, e suas dúvidas sobre o assunto propiciaram uma rica troca de experiências.

Na última cena, o grupo concordava que a mulher seguiria seu caminho e que o homem não faria nada com ela. Outro grupo se manifestou, apontando que na realidade a mulher estaria vulnerável e poderia sofrer algum tipo de ofensa ou mesmo violência física, e que as mulheres não se sentem seguras nas ruas. Ao se colocar em pauta a objetificação e sexualização da mulher, que se insere nas análises das relações de poder, compreende-se que a vulnerabilidade aqui apontada se coloca como um fator de risco para a segurança e a vida das mulheres, violando princípios dos Direitos Humanos.

Após esse primeiro momento, foi aberto o debate entre todos os grupos e, a partir das interações apresentadas, foi-se interligando os conceitos relacionados ao tema da oficina. Dentre

\footnotetext{
2 Em 2015 o Brasil sancionou a Lei 13.104/2015, que introduz uma qualificadora que aumenta a pena para autores de crimes de homicídio praticados contra mulheres. Sua aplicação eleva a pena mínima do crime de 6 para 12 anos e a máxima, de 20 para 30. Por definição, feminicídio é o assassinato de uma mulher pela condição de ser mulher, sendo suas motivações mais usuais o ódio, o desprezo ou o sentimento de perda do controle e da propriedade sobre as mulheres. Mais informações estão disponíveis em https://dossies.agenciapatriciagalvao.org.br/feminicidio.
} 
as experiências compartilhadas, selecionaram-se alguns trechos discursivos dos estudantes para ilustrar o desenvolvimento desses momentos, fazendo paralelamente a análise dos efeitos apreendidos.

Durante a dinâmica inicial da oficina, antes da abertura à discussão, uma estudante lançou no grupo o seguinte pensamento: "Homem e Mulher faz o que quiser!". A provocação aqui percebida se refere aos padrões de gênero que são incutidos em meninos e meninas antes mesmo de nascer, estabelecendo expectativas e modos de ser que visam moldar os sujeitos segundo a norma social (Amanda COSTA; Valeriana PASTOR, 2015). Esta fala remete a uma constante desconstrução que se passa a fazer cotidianamente a partir da compreensão de que determinações biológicas não devem operar como justificativa de padrões culturais, e diz ainda que esta estudante já se encontra nesse movimento de desconstrução.

Entretanto, percebe-se que esse entendimento não é uma regra, mas uma exceção. Pesquisa realizada pela Fundação Instituto de Pesquisas Econômicas (FIPE), a pedido do Instituto Nacional de Estudos e Pesquisas Educacionais Anísio Teixeira (INEP), revela que 93,5\% dos entrevistados possuem preconceito de gênero no ambiente escolar (NÚCLEO DE PESQUISA EM GÊNERO E MASCULINIDADES DA UNIVERSIDADE FEDERAL DE PERNAMBUCO, 2016), dado que preocupa e exige intervenções diretas, pois é na crença que baseia tal preconceito que se encontram as motivações que levam a práticas de violência contra as mulheres.

"O homem é mais ciumento, e a mulher perdoa mais fácil...", foi outra fala apresentada também no início da oficina, fazendo perceber que a socialização dos padrões de gêneros é ensinada de forma tão eficaz que estes são tidos como intrínsecos a todos, sendo considerado estranho e/ou anormal quando as pessoas se desviam dessa representação social que é naturalizada. Essa inscrição social, incorporada à identidade, passa a tecer as relações sociais, sendo assim construídas as desigualdades baseadas nas diferenças. É nesse sentido que a discussão sobre gênero nas escolas se faz necessária, pois é no ambiente escolar que a formação subjetiva se articula com as dimensões políticas e cidadãs (COSTA; PASTOR, 2015).

No desenlace de uma das dinâmicas propostas, um estudante opinou: "Mulher que apanha e não sai de casa é porque gosta de apanhar sim!". Ao questionar o grupo sobre tal afirmação, alguns concordaram e outros discordaram: "se ela não gosta de apanhar, por que não vai embora?" versus "não é simples assim, ele pode ameaçar, bater e até matar ela!". Essas conotações que emergiram foram discutidas com eles com base no ciclo da violência e na percepção dos padrões de gênero, uma vez que, no senso comum, se subentende que a mulher inserida neste ciclo é passiva, submissa e gosta de ser agredida.

Nesse sentido, é importante destacar que "o próprio gênero acaba por se revelar uma camisa de força: o homem deve agredir, porque o macho deve dominar a qualquer custo; e a mulher deve suportar agressões de toda ordem, porque seu destino assim o determina" (SAFFIOTI, 2004 , p. 85). Além da rotinização e do envolvimento afetivo com o autor da agressão há, muitas vezes, dependências de diversas ordens, inclusive emocional, que impedem a mulher de se perceber fora desse contexto, vivendo outras possibilidades. Novamente aqui se percebe que a desnaturalização dos padrões de gênero é uma vertente essencial na prevenção da violência contra a mulher.

No decorrer da oficina surgiu um questionamento com tom de afirmação por um dos estudantes: "se a mulher não quisesse que ninguém olhasse para ela, não usava roupa curta!". Aqui emerge um dos fatores essenciais que legitimam diversas formas de violência: a cultura de estupro. Fundamentada no patriarcado, e consequentemente no machismo e no sexismo, há a visão da mulher como inferiorizada, coisificada e sexualizada, validando a sua subserviência aos homens. Faz-se necessário refletir aqui que, para se atingir uma cultura de paz e respeito, é indispensável desmistificar tais concepções e substituí-las pela noção de que todos e todas merecem respeito à sua dignidade humana, independentemente de seu sexo, gênero ou da roupa que usam. Esse entendimento parte da reflexão apresentada no trabalho do NÚCLEO DE PESQUISA EM GÊNERO E MASCULINIDADES DA UNIVERSIDADE FEDERAL DE PERNAMBUCO (2016), que continua:

A escola é um espaço de educação, portanto de formação para a cidadania. Educar alguém não é apenas transmitir conteúdos e esperar que os/as estudantes, passivamente, absorvam as informações. Educar é, sobretudo, estimular a reflexão crítica e a tomada de posição autônoma e responsável. O respeito e o cuidado com os outros é a base de qualquer relação social. Por isso, educação de qualidade não é aquela que pensa exclusivamente em transmissão de conteúdos ou em resultados, mas, principalmente na promoção do pensamento crítico, como forma de resistência às diversas formas de opressão (NÚCLEO DE PESQUISA EM GÊNERO E MASCULINIDADES DA UNIVERSIDADE FEDERAL DE PERNAMBUCO, 2016, p. 10).

Outra reflexão importante vivenciada nas oficinas partiu da seguinte interrogação feita por uma estudante: "Por que o homem pode ficar com muitas mulheres, e ninguém fala nada, e a mulher que fica com muitos homens fica logo mal falada?". As discussões então mostraram as especificidades intrínsecas aos padrões de gênero, tais como a virilidade, força, impulsividade e 
não expressão de sentimentos, associadas à masculinidade, e a docilidade, fragilidade, instabilidade emocional e recato, associadas à feminilidade. Esses exemplos estão em uma relação de interdependência com as formas de violência, pois a não adequação a esses comportamentos desqualifica a dignidade e o caráter dos sujeitos, caracterizando as violações do respeito ao ser humano (BARRETO; SILVA, 2015).

Nessa direção, a educação em Direitos Humanos na perspectiva de gênero inclui a potencialidade de promover a garantia de direitos por meio de sua afirmação, considerando que "a escola é local de estruturação de concepções de mundo e de consciência social, de circulação e de consolidação de valores, de promoção da diversidade cultural, da formação para a cidadania, de constituição de sujeitos sociais" (BRASIL, 2007, p. 29).

Ao se explicar as diferentes formas de violência contra a mulher, foi percebido que alguns estudantes identificaram conhecer pessoas próximas que passavam por isso. Nessa ocasião, apresentou-se os serviços componentes da rede municipal de apoio à mulher e foram fornecidos materiais informativos (folhetos distribuídos pela Secretaria da Mulher contendo breves definições sobre as formas de violência contra a mulher e os endereços e telefones dos referidos serviços) para que eles pudessem levar para casa e compartilhar essas informações.

Destarte, a partir das discussões produzidas pelos próprios estudantes durante e após as vivências propostas, considera-se que as intervenções realizadas foram positivas, pois foi possível interrogar, examinar e rever conceitos a partir da própria experiência vivida por eles. Assim como traz Mahfoud (1999, p. 146), é necessário que a Psicologia possa "contribuir primeiramente constituindo um espaço para o aluno como pessoa", não apenas como um sujeito passivo e depósito de conhecimentos, e a atuação foi a de permitir essa abertura reflexiva, lidando com as questões daquele contexto específico, que muitas vezes é um contexto institucional cristalizado e desorientado culturalmente.

Ao se abordar o tema da violência contra a mulher, pretendeu-se contribuir para a prevenção desta, sabendo que "a luta pelo fim da violência contra a mulher exige esforços coletivos dos poderes públicos e da sociedade civil" (BANDEIRA; AMORIM, 2013, p. 2). Manifestando-se em um círculo vicioso e sendo legitimada e naturalizada ao longo do tempo por questões de gênero mantidas pelo patriarcado, a violência doméstica em suas diversas facetas exige um comprometimento coletivo, e a academia, por meio da extensão universitária, é um espaço que pode atuar nesta direção, desde que haja responsabilidade e comprometimento com a transformação da realidade que o cerca.

Sendo que a escola pode ser um espaço potencialmente transformador, mas, ao mesmo tempo, reprodutor de desigualdades e preconceitos (ALBERNAZ; LONGHI, 2009; LOURO, 1997; MAHFOUD, 1999), trabalhar tais questões neste território de socialização é de fundamental importância para que os jovens, futuros cidadãos, se conscientizem das realidades sociais $e$ possam exercer sua cidadania de forma democrática, ética, responsável e com respeito para com os outros. Sabe-se que não é possível mudar tudo e todos ao mesmo tempo, e ainda há de se considerar as limitações existentes (institucionais, pessoais e teóricas), mas com vontade e empenho se pode ser agente de transformação, ainda que mínima, e perceber que essa contribuição é gratificante e inspira novas formas de lutar e resistir ante as opressões da atualidade.

\section{Considerações finais}

A realização das intervenções no formato de oficinas tem se revelado uma ferramenta importante para o enfrentamento e a prevenção à violência contra a mulher no âmbito escolar, pois possibilita uma abertura reflexiva frente aos padrões de gênero demarcados socialmente a homens e mulheres, criando assim um ambiente favorável ao processo de desnaturalização desses e das desigualdades daí decorrentes, dentre elas, as justificativas culturais que fundamentam as crenças e percepções acerca da violência contra a mulher.

Além disso, as escolas, que são um dos espaços primários de socialização, se constituem como um espaço favorável na medida em que as crianças e adolescentes, nesse momento de formação pessoal e cidadã, passam a compreender que, desde que tais desigualdades são culturalmente determinadas, são passíveis de transformação. Ainda, a aprendizagem deles também se dissemina em seus espaços próprios de convivência, como a família e a comunidade, favorecendo a difusão das ideias trabalhadas nas oficinas, ampliando, assim, a discussão na sociedade sobre a violência contra a mulher, fortalecendo a visibilidade dessa luta contra a violação de direitos.

A experiência vem se mostrando como necessária, visto, por um lado, o nível crescente dos índices de violência contra a mulher no Brasil, e, por outro lado, os resultados percebidos até então com a realização dessas oficinas. Alguns limites ainda precisam ser superados, como a resistência de alguns professores em participar do momento da oficina, preferindo ir realizar outras atividades profissionais, e a demanda de escolas para participar do Projeto, pois o número de extensionistas não consegue atender a todas e, por isso, em alguns momentos foi preciso abrir mão da 
sistematicidade das oficinas (semanalmente) em prol de uma abrangência mais ampla de escolas ao recebimento do projeto.

Conclui-se que tal projeto é de fundamental importância no cenário atual, visando à diminuição das consequências do patriarcado na sociedade e à prevenção das diversas formas de violação dos direitos das mulheres. Por fim, considerando que o presente relato de experiência se constitui a partir de uma amostra limitada e dentro de um contexto específico, é sugerido que outros estudos sejam realizados relatando os resultados do projeto Lei Maria da Penha vai às escolas nas demais cidades do estado de Pernambuco, bem como que possam abranger um período de tempo maior para, assim, se verificar os avanços efetivos a médio e longo prazo dessas ações.

\section{Referências}

ALBERNAZ, Lady Selma Ferreira; LONGHI, Márcia. "Para Compreender Gênero: uma ponte para relações igualitárias entre homens e mulheres". In: SCOTT, Parry; LEWIS, Liana; QUADROS, Marion Teodósio de (Orgs.). Gênero, diversidade e desigualdades na educação: interpretações e reflexões para formação docente. Recife: EDUFPE, 2009. p. 75-96.

BANDEIRA, Katherine Lages Contasti; AMORIM, Elba Ravane Alves de. De Olhos Abertos Contra A Violência. Curso de capacitação dos profissionais especializados e da rede de atendimento à mulher em situação de violência em Caruaru-PE, 2013.

BARDIN, Laurence. Análise de Conteúdo. 3. ed. Lisboa: Edições 70, 2007.

BARRETO, Raqueline Farias; SILVA, Josué Barreto. "Educação em Direitos Humanos em uma perspectiva de gênero na escola". Revista de Educação Pública, Rio de Janeiro, v. 15, n. 21 , p. 07-15, out. 2015. Disponível em http://educacaopublica.cederj.edu.br/revista/artigos/educacao-em-direitoshumanos-em-uma-perspectiva-de-genero-na-escola. Acesso em 08/04/201 7.

BOURDIEU, Pierre. A Dominação Masculina. 9. ed. Rio de Janeiro: Bertrand Brasil, 2010.

BRASIL. Constituição da República Federativa do Brasil, 1988. Brasília, 1988. Disponível em http:// www.planalto.gov.br/ccivil_03/constituicao/constituicao.htm.

BRASIL. Convenção Interamericana para prevenir, punir e erradicar a violência contra a mulher, 1994. Belém do Pará, 09/06/1994. Disponível em http://www.cidh.org/Basicos/Portugues/ m.Belem.do.Para.htm.

BRASIL. Decreto $n^{\circ} 4.377$, de 13 de setembro de 2002. Promulga a Convenção sobre a Eliminação de Todas as Formas de Discriminação contra a Mulher, de 1979 [...]. Brasília, 2002. Disponível em http://www.planalto.gov.br/ccivil_03/decreto/2002/D4377.htm.

BRASIL. Plano Nacional de Educação em Direitos Humanos. Comitê Nacional de Educação em Direitos Humanos. Brasília: Secretaria Especial dos Direitos Humanos, Ministério da Educação, Ministério da Justiça, UNESCO, 2007.

BRASIL. Lei 11.340, de 07 de agosto de 2006, que dispõe sobre mecanismos para coibir a violência doméstica e familiar contra a mulher. Brasília: Câmara dos Deputados, Edições Câmara, 2006 .

BRASIL. Plano Nacional de Políticas para as Mulheres, 2005. Brasília: Presidência da República; Secretaria Especial de Políticas para as Mulheres, 2006b. Disponível em http://www.observatoriode genero.gov.br/eixo/politicas-publicas/pnpm/i-pnpm//\%20PNPM_versao\%20compacta.pdf.

BRASIL. PRESIDÊNCIA DA REPÚBLICA. SECRETARIA DE POLÍTICAS PARA AS MULHERES. Plano Nacional de Políticas para as Mulheres. Brasília: Secretaria de Políticas para as Mulheres, 2013.

CONSELHO FEDERAL DE PSICOLOGIA. Referências Técnicas para Atuação de Psicólogas(os) em Programas de Atenção à Mulher em Situação de Violência. Brasília: Conselho Federal de Psicologia, 2012.

COSTA, Amanda Samara do Nascimento; PASTOR, Valeriana Porto. "Projeto de Extensão Gênero e Educação: um olhar sobre o contexto escolar". In: XVIII ENCONTRO NACIONAL DA ABRAPSO: psicologia social e os atuais desafios ético-políticos no Brasil, XVIII, 2015, Fortaleza, ABRAPSO. Anais... Fortaleza: Universidade Federal do Ceará/ABRAPSO, 2015. p. 538. Disponível em http:// www.encontro2015.abrapso.org.br. Acesso em 24/03/2017.

DELPHY, Christine. "Patriarcado (teorias do)". In: HIRATA, Helena; LABORIE, Françoise; LE DOARÉ, Hélène; SENOTIER, Danièle (Orgs.). Dicionário Crítico do Feminismo. São Paulo: EDUNESP, 2009. p. 173-178. 
DIÁRIO OFICIAL DO MUNICÍPIO DE CARUARU. Decreto $n^{\circ}$ 035, de 17 de março de 2016. Institui o programa Maria da Penha vai às Escolas. Caruaru, 2016.

FORPROEX. FÓRUM DE PRÓ-REITORES DE EXTENSÃO DAS UNIVERSIDADES PÚBLICAS BRASILEIRAS. POlítica Nacional de Extensão Universitária. Manaus-AM, 2012. Disponível em http://www.renex.org.br/ documentos/2012-07-13-Politica-Nacional-de-Extensao.pdf. Acesso em 23/02/2015.

GIL, Antônio Carlos. Métodos e Técnicas de Pesquisa Social. 5. ed. São Paulo: Atlas, 1999.

GOVERNO DO ESTADO DE PERNAMBUCO. Plano Estadual para Prevenir, Punir e Erradicar a Violência Contra as Mulheres. Recife: Secretaria da Mulher, 2008.

LOURO, Guacira Lopes. Gênero, Sexualidade e Educação: uma perspectiva pós-estruturalista. Petrópolis: Vozes, 1997.

MAHFOUD, Miguel. "Plantão Psicológico na Escola: uma experiência". In: MORATO, Henriette Tognetti Penha (Org.). Aconselhamento Psicológico Centrado na Pessoa: novos desafios. São Paulo: Casa do Psicólogo, 1999. p. 75-85.

NEIVA, Kathia M. C. Intervenção Psicossocial: aspectos teóricos, metodológicos e experiências práticas. São Paulo: Vetor, 2010.

NÚCLEO DE PESQUISA EM GÊNERO E MASCULINIDADES DA UNIVERSIDADE FEDERAL DE PERNAMBUCO. Gênero nas escolas: Duas décadas de ações pelo fim do preconceito no Brasil. Recife: GEMA/ UFPE, 2016. Disponível em http://gema-ufpe.blogspot.com.br/2016/07/lancamento-da-cartilhagenero-nas.html. Acesso em 09/04/2017.

ONU. Declaração Universal dos Direitos Humanos, 1948. Paris, 1948. Disponível em https:// nacoesunidas.org/wp-content/uploads/2018/10/DUDH.pdf.

ONU MULHERES. Mapa da violência 2015, 2016. Disponível em http://www.onumulheres.org.br/wpcontent/uploads/2016/04/MapaViolencia_2015_mulheres.pdf.

SAFFIOTI, Heleieth I. B. Gênero, patriarcado, violência. São Paulo: Fundação Perseu Abramo, 2004.

SANTOS, Cecília MacDowell; IZUMINO, Wânia Pasinato. "Violência Contra as Mulheres e Violência de Gênero: notas sobre estudos feministas no Brasil". Estudios Interdisciplinários de America Latina y El Caribe, Universidade de Tel Aviv, v. 16, n. 01, p. 147-164, 2005. Disponível em http:// www.nevusp.org/downloads/down083.pdf. Acesso em 19/12/2018.

Kristine Kelly de Albuquerque (k5747albuquerque@gmail.com) é graduada em Psicologia pelo Centro Universitário do Vale do Ipojuca - UNIFAVIP WYDEN. Possui experiência nas seguintes áreas: clínica, educacional, saúde mental, social e jurídica. Tem interesse nos seguintes temas: Clínica Terapêutica (Fenomenologia, Existencialismo e Humanismo); Atenção à Saúde e Saúde Mental (com ênfase no cuidado a usuários/as de álcool e outras drogas); Gênero; Interseccionalidades; Psicologia Jurídica.

\section{COMO CITAR ESSE ARTIGO DE ACORDO COM AS NORMAS DA REVISTA}

ALBUQUERQUE, Kristine Kelly de. "Diálogos de gênero na educação: considerações sobre o projeto Lei Maria da Penha vai às escolas". Revista Estudos Feministas, Florianópolis, v. 28, n. 2, e60485, 2020.

\section{CONTRIBUIÇÃO DE AUTORIA}

Não se aplica.

FINANCIAMENTO

Não se aplica.

\section{CONSENTIMENTO DE USO DE IMAGEM}

Não se aplica. 


\section{APROVAÇÃo DE COMITÊ DE ÉtICA EM PESQUISA}

Não se aplica.

\section{CONFLITO DE INTERESSES}

Não se aplica.

LICENÇA DE USO

Este artigo está licenciado sob a Licença Creative Commons CC-BY International. Com essa licença você pode compartilhar, adaptar, criar para qualquer fim, desde que atribua a autoria da obra.

\section{HISTÓRICO}

Recebido em 29/11/2018

Reapresentado em 29/10/2019

Aprovado em 10/02/2020

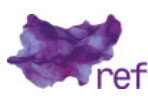

